\section{Britain's binary higher education}

SIR - Few would disagree with your view (Nature 2 February, p.400) that the United Kingdom's binary system of higher education is divisive, but $I$ feel that your leading article contained some errors.

The local authority, or maintained, sector of higher education consists of many more institutions than the thirty (not twenty-six) polytechnics in England and Wales. These include the colleges and institutes of higher education and the Scottish central and local authority institutions.

Polytechnics were not designated as degree-giving institutions. They, in common with other maintained institutions, had in their constituent colleges offered degree courses for many years, usually validated by the University of London. Today, polytechnics are proud of the range of courses they offer leading to higher diplomas, professional qualifications and degrees - the degrees being validated by the Council for National Academic Awards.

It is misleading to suggest that the polytechnics have attempted to ape the universities. Their range and diversity of work, the variety of modes of study, their vocational emphasis, links with industry, commerce and the professions and ties with the regional and local community combined with their national roles fully justify their claim that they have been highly successful in achieving the objectives set out in the 1966 White Paper which included the establishment of "a strong and distinctive sector which is complementary to the universities".

Turning to the proposed Polytechnics Central Admissions System (PCAS), it must be placed on record that the initiative came from the Committee of Directors of Polytechnics (CDP). It is CDP which has successfully negotiated with the University Central Council on Admissions (UCCA), not the Department of Education and Science (DES), and CDP which has successfully negotiated with DES the offer of a grant towards the cost of setting up PCAS. What should also be placed on record is CDP's appreciation of the positive response of UCCA and of DES. Using your own wording, it is a nonsense to say that PCAS will run for a trial period of two years. It is anticipated that there will be two financial years in which expenditure will be incurred in setting up the system before any income received from participating institutions and applicants. Once the system has been established, it is expected to be self-financing.

In suggesting that confusion may arise because applicants using UCCA and PCAS will be required to complete two separate forms, it is worth stressing that polytechnic applicants now have to complete a separate form for each polytechnic to which they apply, as well as an UCCA form if they are also applying to universities. CDP would venture to suggest that two forms will be a marked improvement.

The commitment of CDP to consider at an early stage the possibility of extending PCAS to cover full-time and sandwich degree courses in other local authority institutions is evidence enough that this initiative is not being regarded as the end of the road of rationalizing the applications jungle. But it would be impracticable to attempt to do so all at once. In that context, the initiative was never seen by CDP as a first step to removing the binary line. Others may read into it what they will.

It is a great pity that despite three lengthy telephone calls to the CDP office, and the availability of UCCA and DES press releases, your journal should have so completely misunderstood the nature of polytechnics and of what is being proposed.

M.S. LEWIS

\section{Committee of Directors}

of Polytechnics,

309 Regent Street,

London WIR TPE, UK

SIR - The "Binary is divisive" column (Nature 2 February, p.400) makes some fair points and the desirability of greater diversity in higher education would be endorsed by many. However, in discussing this matter at least three factors differentiating polytechnics from universities need to be considered and these are, to some extent, run together in the argument presented for scrapping the binary line. The three factors are non-autonomy/ autonomy, lower unit costs/higher unit costs and more vocational/less vocational approaches to teaching.

The article does not make clear whether the writer considers that polytechnics should become chartered institutions but there are good arguments that this should happen in some institutions now and in others in the course of time. Discussion of comparative costs (which in practice vary greatly from institution to institution within both groups) tends to be accompanied by a deal of acrimony. Part of the differential relates to salary levels, part to student loads and part to the heavier research involvement of university staff. Unfortunately too much attention is focused on the first of these and indeed, abolition of the binary line tends, in the eyes of many academics in both sectors, mainly to mean unifying of salary structure.

The third factor is in many ways the most important. Many of those who, like myself, have experience of the ways in which polytechnics operate and who value the excellent work done in many departments find it a tragedy that so many polytechnics have moved away from emphasis on vocational and part-time education in the way that the article portrays. What is needed is a resolve to get back to the founding principles and it does not follow that abolition of the dividing line will produce this. Rather, I suspect, the drift away from doing useful things would be accelerated. There may be another danger here for the universities. Of course much directly vocational work in teaching and research is done, as it always has been, in universities. It would, however, be a tragedy if the vocational test were to be strictly applied to what universities do.

My view is that what the United Kingdom needs is a sober, considered and detached appraisal of what the shape and scope of higher education over the next few decades should be and serious political consideration ought to be given to formulating such a policy as soon as possible.

J. A. BEARDMORE

Department of Genetics,

University College of Swansea,

Swansea SAZ 8PP, UK

\section{NASA's spending}

SIR - I agree wholeheartedly with your argument that the National Aeronautics and Space Administration (NASA) tends to live by pushing for huge new projects and hastily devising rationales for them afterwards (Nature 307, 1; 1984). However, your second theme - that the manned station would be an outright disaster for space sciences and astronomy - is a distinctly false charge.

From the start, NASA's design for the station has included a large unmanned platform, carrying astrophysical instrumentation, at a distance of several thousand metres from the manned station. This design, from the point of view of space science, provides the best of both possible worlds. It provides freedom from interference by crew motions or vented-gas contamination (a far more serious shuttle and manned-platform problem which Nature failed to mention). But it also allows regular instrument repair and maintenance by a nearby manned crew - a very important factor, as Spacelab-1, Skylab, Solar Max and a legion of other unmanned spacecraft have shown us. In addition, the servicing of other scientific spacecraft has been strongly indicated as a station justification.

Your sneer that the station will serve as a base for research on "whether you can make the perfect ball-bearing in space" also misses the point. From the start, zero-g manufacturing - particularly of drugs has been recognized as the single greatest justification for a centralized station, manned or unmanned. In sum, the rationale for a manned station remains extremely wobbly - especially as compared to an unmanned station with frequent maintenance-crew visits - but it is far stronger than Nature states.

R. BRUCE MOOMAW

2953 Oakleaf Drive,

Cameron Park, California 95682, USA 